\title{
Índices morfofisiológicos e clorofila de hortelã-pimenta cultivadas sob diferentes sistemas de cultivos
}

A hortelã-pimenta (Mentha x piperita) é atualmente cultivada em todo o mundo. Utilizada como tempero em inúmeros pratos culinários assim como planta medicinal, também fornece óleo essenciais que podem ser extraídos da planta. 0 sistema mais adequado para produção de hortelã-pimenta é de grande interesse, pois técnicas alternativas como o sistema hidropônico e semi-hidropônico podem reduzir o uso intensivo dos solos, além de diminuir doenças que afetam o solo. Objetivou-se com este trabalho avaliar o efeito de diferentes formas de cultivo (solo, semi-hidropônico e hidropônico) e formas de propagação (sementes e mini-estaçs) na produção de biomassa em Hortelã-pimenta (Mentha x piperita) no sudeste paraense. 0 experimento foi realizado na Universidade Federal Rural da Amazônia e em uma propriedade rural voltada à produção de hortaliças hidropônicas - B\&A Hidroponia. O delineamento experimental se deu em esquema fatorial 3×2, com 3 sistemas e duas formas de propagação, sendo os sistemas: 1-Hidroponia; 2- Semi-hidroponia; 3 - Solo, e as formas de propagação por via mini-estaca e semente com cinco repetições. As médias comparadas pelo teste de Tukey a $5 \%$ de probabilidade. Foram avaliadas as características altura de plantas ( $\mathrm{cm}$ ), número de folhas, massa fresca $(\mathrm{g})$, massa seca $(\mathrm{g})$, área foliar $\left(\mathrm{cm}^{2}\right)$, largura foliar $(\mathrm{cm})$, comprimento foliar $(\mathrm{cm})$, fator de forma, perímetro foliar $(\mathrm{cm})$, produtividade $(\mathrm{g})$, ciclo, médias da razão de área foliar (RAF), razão de peso das folhas (RPF), área foliar específica (AFE), peso específico foliar (PEF), quantidade de água na parte aérea (QAPA) índice de área foliar (IAF) e clorofila a, b e total (ICF). A forma de propagação utilizada através de mini-estaca se mostrou eficiente para o cultivo de hortelã-pimenta, promovendo um menor ciclo em todos os sistemas observados, sendo em hidroponia 43 dias de ciclo, semi-hidroponia e solo ambas com 45 dias ciclo, na produção via semente as plantas apresentaram em hidroponia 72 , semi-hidroponia 83 e solo 102 dias de ciclo. As maiores produtividades foram encontradas nos sistemas solo e semi-hidroponia, através da forma de propagação por mini-estaca. Nos parâmetros morfofisiológicos o cultivo em sistema hidropônico e semi-hidropônico em sua generalidade foi o que apresentou melhores condições para a produção de plantas de hortelã-pimenta através de mini-estaca. Os valores de clorofila não divergiram quanto as formas de propagação evidenciando tanto mini-estaca quanto semente, boas condutoras no cultivo de plantas na produção de pigmentos fotossintéticos, já em relação ao sistema, o cultivo em solo foi o que se mostrou mais promissor.

\section{Morphophysiological indices and chlorophyll of mint pepper plants cultivated under different cultivation systems}

\begin{abstract}
Peppermint (Mentha x piperita) is currently grown worldwide. Used as a spice in many dishes and as well as medicinal, the plant provides essential oils that can be extracted from the plant. The most suitable system for peppermint production is have great interest, as alternative techniques such as the hydroponic and semi-hydroponic system that can reduce intensive land use, as well as reducing soil diseases that affect plant production. The objective of this work was to evaluate the effect of different cultivation forms (soil, semi-hydroponic and hydroponic) and propagation forms (seeds and mini-cuttings) on the production of peppermint (Mentha x piperita) in southeastern of Pará. The experiment was conducted at the Federal Rural University of Amazonia and in a rural property located in the in rural area district Condomínio Rural, focused on the production of hydroponic vegetables - B\&A Hidroponia. The experimental outlining was a $3 \times 2$ factorial scheme, with 3 systems and two propagation forms: 1-Hydroponics; 2-Semi-hydroponics; 3 - Soil, and the forms of propagation was mini-cutting and seed with five repetitions. The means compared by Tukey test at $5 \%$ probability. Plant height $(\mathrm{cm})$, number of leaves, fresh mass $(\mathrm{g})$, dry mass $(\mathrm{g})$, leaf area $\left(\mathrm{cm}^{2}\right)$, leaf width $(\mathrm{cm})$, leaf length $(\mathrm{cm})$, shape factor, perimeter $(\mathrm{cm}$ ), vield (g) cycle, leaf area ratio (RAF), leaf weight ratio (RPF), specific leaf area (AFE), leaf specific weight (PEF), water content (DAPA) leaf area index (IAF) and chlorophyll , band a, band soil 102 days cycle. The highest yields were found in the soil and semi-hydroponics systems through mini-cutting propagation. In the morph, physiological parameters the cultivation in hydroponic and semi-hydroponic system in general was the one that presented better conditions for the production of peppermint plants through mini-cuttings. Chlorophyll values did not differ as the propagation forms evidencing both mini-cut and seed, good conducive in the cultivation of plants in the production of photosynthetic pigments, whereas in relation to the system, the cultivation in soil was the most promising.
\end{abstract}

Keywords: Mentha x piperita; Hydroponics; Semi-hydroponics; Mini-cutting; Productivity.

Topic: Desenvolvimento, Sustentabilidade e Meio Ambiente

Reviewed anonymously in the process of blind peer.

Luana Keslley Nascimento Casais (D)

Universidade Federal Rural da Amazônia, Brasil

http://lattes.cnpq.br/8075409193627849

http://orcid.org/0000-0001-7197-5524

luana.casais@gmail.com

Luciana da Silva Borges (id

Universidade Federal Rural da Amazônia, Brasil

http://lattes.cnpq.br/4533722536181534

http://orcid.org/0000-0002-1194-6411

luciana.borges@ufra.edu.br

Maria do Bom Conselho Lacerda Medeiros (iD)

Universidade Federal Rural da Amazônia, Brasil

http://lattes.cnpq.br/4581189119190265

http://orcid.org/0000-0002-1364-6877

melyagronomia@hotmail.com

d

DOI: 10.6008/CBPC2179-6858.2020.003.0024
Received: $15 / 03 / 2020$

Approved: 20/04/2020

Manoel Euzebio de Souza (iD

Universidade do Estado de Mato Grosso, Brasil

http://lattes.cnpq.br/9359831090013191

http://orcid.org/0000-0003-0458-240X

m.euzebio@unemat.br

Denilze Santos Soares (iD)

Universidade Federal Rural da Amazônia, Brasil

http://lattes.cnpq.br/0560995243358445

http://orcid.org/0000-0001-9121-6234

denilzesoares@gmail.com

Referencing this:

CASAIS, L. K. N.; BORGES, L. S.; MEDEIROS, M. B. C. L.; SOUZA, M. E.; SOARES, D. S.. Índices morfofisiológicos e clorofila de hortelã-pimenta cultivadas sob diferentes sistemas de cultivos. Revista Ibero

Americana de Ciências Ambientais, v.11, n.3, p.304-316, 2020. DOI: http://doi.org/10.6008/CBPC2179-6858.2020.003.0024 


\section{INTRODUÇÃO}

A hortelã-pimenta é uma planta herbácea pertencente à família Lamiaceae, possuindo uma grande quantidade de variedades produzidas. É originária da Ásia e atualmente cultivada em todo o mundo. Brasil (2015), diz que a hortelã-pimenta (Mentha x piperita) é um híbrido entre Mentha aquática e Mentha spicata. É uma planta naturalizada, não endêmica do Brasil. Sua distribuição geográfica no Brasil abrange as regiões Norte, Nordeste, Centro-oeste, Sudeste e Sul, pois apresentam ter um ambiente propício como luz, umidade e temperatura adequados para o seu cultivo.

A forma de cultivo apresenta-se como importante aliada para a obtenção de plantas maiores, sadias e próprias para serem utilizadas. Entretanto é importante analisar qual o melhor meio de se produzir, seja ele em solo, sistema hidropônico ou semi-hidropônico. Segundo Guedes (2015), o meio de cultivo é o principal fator a ser analisado a fim de que características desejáveis sejam produzidas em abundância. Outro ponto importante que deve ser levado em consideração é a forma de propagação da hortelã-pimenta.

A técnica de propagação assexuada usando a estaquia em condições favoráveis podem ser usadas para a formação de clones, demonstrando um avanço no estabelecimento do cultivo de plantas (DINALLI et al., 2013). O método de estaquia possibilita a obtenção de várias plantas idênticas a partir de uma única planta matriz (GRANDI, 2014) enquanto que o cultivo por sementes nos possibilitará plantas com características genotípicas diferentes.

Segundo Lourenco (2015) uma estratégia utilizada na produção da hortelã-pimenta é reunir algumas características edafoclimáticas como instalação da cultura, através da escolha da forma de cultivo. Dentre as formas de cultivo se tem a hidroponia, que é constituída uma técnica alternativa de cultivo protegido (BEZERRA NETO et al., 2012). O sistema hidropônico permite geralmente que as plantas apresentam crescimento mais rápido, pois a absorção de água e nutrientes é facilitada, pelo fato de haver contato direto da raiz com a solução (PARDOSSI et al., 2017).

Outra forma de cultivo que vem ganhando destaque para cultivo da hortelã-pimenta é semihidropônico, que segundo Sizenando Neto et al. (2017) exige um menor espaço, a produção de hortaliças e plantas podem ser feitas em qualquer lugar, qualquer clima, por isso nos dias atuais vem sendo uma das técnicas muito utilizadas pelos produtores, mas ainda sim a forma tradicional de cultivo de hortelã-pimenta ainda é o cultivo em solo, de onde se extrai a maior parte da produção mundial.

O solo constitui uma das principais vias de cultivo da hortelã, pois nele é possível obter todo os nutrientes necessários para sua produção, bem como é o recurso de fácil acesso para qualquer agricultor, no entanto com o fim de facilitar o manejo, outras formas de cultivo são empregadas como hidroponia e semihidroponia já citado anteriormente.

Na literatura ainda são escassos os trabalhos analisando a planta de hortelã-pimenta submetida a diferentes sistemas, bem como suas formas de propagação. Com isso se faz necessário pesquisas que alavanquem a área de produção dessa cultura. Sendo assim, objetivou-se com este trabalho avaliar o efeito de diferentes formas de cultivo (solo, semi-hidropônico e hidropônico) e formas de propagação (sementes e 
mini-estacas) na produção de biomassa em Hortelã-pimenta (Mentha x piperita) no sudeste paraense.

\section{MATERIAIS E MÉTODOS}

O experimento foi conduzido na Universidade Federal Rural da Amazônia, campus de Paragominas na área experimental de Horticultura, no laboratório multifuncional da instituição e em uma propriedade rural localizada no bairro Condomínio Rural, voltada à produção de hortaliças hidropônicas - B\&A Hidroponia, é uma empresa que atua no município desde o ano de 2016, e tem como sua principal produção a cultura da alface, jambu, salsa e rúcula. Outras espécies estão sendo inseridas ao ambiente de cultivo conforme

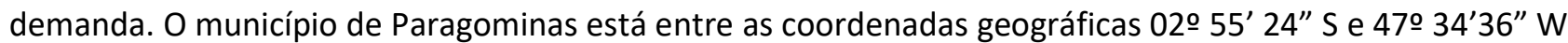
(EMBRAPA, 2008). O clima da região é do tipo "Aw", segundo a classificação de Köppen, isto é, tropical chuvoso com estação seca bem definida, com temperatura média anual de $26,5 \circ \mathrm{C}$. A umidade relativa do ar varia de $70 \%$ a $90 \%$ (RODRIGUES et al., 2002).

Realizado entre os meses de Julho a Outubro de 2019. Onde foi adotado o delineamento experimental inteiramente casualisado (DIC) em esquema fatorial $3 \times 2$, com 3 sistemas de cultivo e duas formas de propagação, sendo os sistemas: 1-Hidroponia; 2- Semi-hidroponia; 3- Solo, e as formas de propagação por via mini-estaca e semente com cinco repetições, sendo 4 plantas por repetição.

A estrutura da hidroponia consiste de 3 (três) estufas construídas em aço estrutural e madeira, cobertas com filme plástico (150 microns) e com as laterais completamente fechadas com sombrite vermelha termofletora $35 \%$. Uma casa com motor-bomba, onde ficam os recipientes com a solução nutritiva, as estruturas de bombeamento e painel de controle. A temperatura média dentro das estufas de hidroponia gira em torno dos $30^{\circ} \mathrm{C}$, e o pH da solução fica em torno de 5 a 7.

As bancadas de hidroponia são compostas por canos de polietileno específicos para hidroponia, com uma declividade de $8 \%$ e o sistema semi-hidropônico são duas estufas construídas em madeira e cobertas com filme plástico (150 microns), possui bancadas (Figura 1B) em madeira nas dimensões 5 x 1,20 m, que são preenchidas com um material inerte ideal para o cultivo (areia lavada e casca de arroz carbonizada).

O sistema em solo possui dois canteiros constituídos de terra preta, ambos apresentam $5 \mathrm{~m}$ de comprimento por 1 metro de largura, não havendo cobertura nem proteção lateral, estando eles a céu aberto. $\mathrm{O}$ espaçamento entre plantas adotado foi de $30 \times 30 \mathrm{~cm}$, em fileira dupla e $20 \mathrm{~cm}$ entre canteiros. A irrigação foi através de mangueiras gotejadoras. A solução nutritiva utilizada no cultivo tanto em hidroponia quanto semi-hidroponia é preparada se utilizando $650 \mathrm{~g} / 1000 \mathrm{~L}$ de Dripsol Alface, $650 \mathrm{~g} / 1000 \mathrm{~L}$ de Calcinit, 20 g/1000L de Kelamyth MP6 e 10 g/1000L. A renovação completa da solução é realizada a cada 20 dias.

A semeadura na hidroponia, para o cultivo hidropônico e semi-hidropônico foi em espuma fenólica com uma semente por célula, para o cultivo em solo, foi em no viveiro da UFRA, campus Paragominas, em bandejas de poliestireno expandido de 128 células com 2 sementes por célula, até que as mudas obtivessem altura de $10 \mathrm{~cm}$ para transplante. Passados 39 dias as mudas na hidroponia foram transplantadas para os canais de cultivo hidropônico e semi-hidropônico, as mudas produzidas em solo só atingiram ponto de transplante em torno dos 60 dias da semeadura, sendo em seguida transplantadas para os canteiros. As 
coletas foram realizadas em diferentes períodos conforme a progressão da cultura nos diferentes sistemas de cultivo.

A hortelã produzida através de sementes em sistema hidropônico foi a primeira ser coletada totalizando ciclo de 72 dias, a segunda coleta foi realizada nas plantas produzidas por mini-estacas em sistema hidropônico e nas plantas produzidas por sementes em sistema semi-hidropônico, totalizando ciclo de 43 dias e 83 dias respectivamente, finalizando as com as plantas produzidas em sistema semi-hidropônico através de mini-estacas e no cultivo em solo por sementes e mini-estacas, totalizando ciclo de 45, 102 e 45 dias, respectivamente.

Foram colhidas e avaliadas quatro plantas de cada repetição, totalizando 20 plantas por sistema de cultivo e 40 plantas por cada forma de propagação, quando atingiram o máximo desenvolvimento vegetativo. A colheita das plantas foi realizada no período da tarde onde foram selecionadas e transportadas imediatamente ao laboratório para se efetuar a avaliação das mesmas. As partes foram lavadas em água corrente para retirada do calor de campo e grandes impurezas e prosseguiu-se com as respectivas avaliações em laboratório: altura de plantas $(\mathrm{cm})$ com a utilização régua métrica, número de folhas contados manualmente, massa fresca $(\mathrm{g})$, massa seca $(\mathrm{g})$ a partir de pesagem em balança digital de precisão, área foliar $\left(\mathrm{cm}^{2}\right)$, largura foliar $(\mathrm{cm})$, comprimento foliar $(\mathrm{cm})$, fator de forma, perímetro foliar $(\mathrm{cm})$ obtidos a partir do equipamento Medidor de Área Foliar AM350 $\left(\mathrm{cm}^{2}\right)$, produtividade (g) e ciclo: contagem de dias da semeadura a colheita.

As médias da razão de área foliar (RAF): Determinada através da razão entre os valores da área foliar total e massa seca total $\left(\mathrm{dm}^{2} \mathrm{~g}^{-1}\right)$, razão de peso das folhas (RPF): A razão de peso de folhas é calculada pela razão entre a massa seca de folhas e a massa seca total ( $g$ g-1), área foliar específica (AFE): estimada pela superfície das folhas e sua massa seca $\left(\mathrm{dm}^{2} \mathrm{~g}^{-1}\right)$, peso específico foliar (PEF) ( $\mathrm{g} \mathrm{cm}^{-2}$ por conjunto de plantas): O peso específico foliar foi estimado através da divisão da massa seca da parte aérea pela área foliar ( $\mathrm{g} \mathrm{dm}$ ${ }^{2}$ ), quantidade de água na parte aérea (QAPA: (g por conjunto de plantas): A quantidade de água na parte aérea foi obtida através da diferença entre a massa de matéria fresca e seca da parte aérea das plantas avaliadas (g), índice de área foliar (IAF): determinado através da razão entre os valores da área foliar total e área de solo ocupada pelas plantas ( $\mathrm{cm}^{2} /$ planta) e clorofila $\mathrm{a}, \mathrm{b}$ e total (ICF) medidos através do aparelho Clorofilog, calculado com base na absorção de luz em comprimentos de onda característicos da clorofila, através de um scanner que mapeia toda a folha. Todos os dados obtidos foram analisados estatisticamente através da análise de variância, com teste F. Quando houve significância para o fator foi aplicado teste de Tukey (5\%) para a comparação de médias. Todas as análises realizadas foram feitas pelo programa SISVAR (FERREIRA, 2000).

\section{RESULTADOS E DISCUSSÃO}

Verificou-se efeito significativos na interação entre os fatores formas de propagação e sistema de plantas de hortelã-pimenta para as características avaliadas: altura, número de folhas, massa fresca, massa seca e produtividade. Demonstrando que tanto o fator forma de propagação como o fator sistema 
influenciaram nas qualidades fitotécnicas das plantas de hortelã-pimenta (Tabela 1).

A forma de cultivo por meio de mini-estaca, mostrou resultados significantes em relação a forma de cultivo através de sementes, obtendo os melhores resultados em todos os sistemas na variável altura (Tabela 1). O sistema hidropônico obteve melhor resultado em ambos os sistemas. Almeida (2018), diz que a altura da biomassa é uma característica que é influenciada pela adubação e também pelo tempo de permanência da planta no sistema, alcançando média de $34,6 \mathrm{~cm}$ de altura para plantas de hortelã cultivadas sob diferentes doses de jitirana, valores esses similares aos encontrados neste trabalho.

Tabela 1: Indicadores morfológicos em plantas de Hortelã-pimenta, cultivadas por diferentes formas de propagação e sistemas de cultivos, onde AT-altura, NF-Número de folhas, MF- Massa fresca, MS- Massa seca e P- Produtividade. Paragominas/PA.

\begin{tabular}{|l|l|l|l|l|l|}
\hline SISTEMA & AT $(\mathrm{cm})$ & NF & MF $(\mathrm{g})$ & MS $(\mathrm{g})$ & P $(\mathrm{g})$ \\
\hline MINI-ESTACA & & & & & \\
\hline Solo & $22,80 \mathrm{cA}$ & $448,9 \mathrm{aA}$ & $71,67 \mathrm{aA}$ & $6,57 \mathrm{cB}$ & $286,69 \mathrm{aA}$ \\
\hline Semi-hidroponia & $30,30 \mathrm{bA}$ & $220,9 \mathrm{bA}$ & $74,59 \mathrm{aA}$ & $10,77 \mathrm{bA}$ & $298,36 \mathrm{aA}$ \\
\hline Hidroponia & $39,05 \mathrm{aA}$ & $464,0 \mathrm{aA}$ & $52,45 \mathrm{bB}$ & $12,83 \mathrm{aA}$ & $209,79 \mathrm{bB}$ \\
\hline SEMENTE & & & & & \\
\hline Solo & $18,55 \mathrm{bB}$ & $318,9 \mathrm{cB}$ & $37,29 \mathrm{cB}$ & $10,67 \mathrm{aA}$ & $149,18 \mathrm{cB}$ \\
\hline Semi-hidroponia & $28,50 \mathrm{aB}$ & $478,6 \mathrm{aB}$ & $47,37 \mathrm{bB}$ & $5,59 \mathrm{bB}$ & $189,50 \mathrm{bB}$ \\
\hline Hidroponia & $30,15 \mathrm{aB}$ & $396,1 \mathrm{bB}$ & $61,40 \mathrm{aA}$ & $11,22 \mathrm{aB}$ & $245,59 \mathrm{aA}$ \\
\hline Forma de propagação & $* *$ & NS & $* *$ & $* *$ & $* *$ \\
\hline Sistema & $* *$ & $* *$ & $* *$ & $* *$ \\
\hline FP $\times$ & $* *$ & $* *$ & $* *$ & $* *$ & $* *$ \\
\hline CV (\%) & 8,15 & 5,32 & 8,91 & 4,89 & 8,91 \\
\hline
\end{tabular}

Médias seguidas pela mesma letra maiúscula corresponde a forma de propagação não diferem entre si, médias seguidas pela mesma letra minúscula corresponde a um sistema não diferem entre si, pelo teste de Tukey, a 5\% de probabilidade, ${ }^{* *}=$ significativo a $5 \%$ de probabilidade; FP x S: Interação forma de propagação e sistema; ns=não significativo.

Para o número de folhas, houve resposta significativa para a interação entre forma de propagação e sistema (Tabela 1). Não havendo resposta significativa quanto à forma de propagação. Para sistema, solo e hidropônico apresentaram melhores resultados. Carvalho (2015) diz que há uma tendência para o aumento no número de folhas de hortelã quando cultivadas no solo com um teor mais elevado de $\mathrm{MO}$, o referido autor em sua pesquisa analisando o efeito da correção orgânica e da fertirrigação na cultura da hortelã-pimenta, verificou um aumento do número de folhas de hortelã-pimenta chegando a média de 350 folhas/planta.

Com relação a massa fresca, houve interação significativa para interação entre FP x S, desta forma foi realizado o desdobramento entre os fatores, onde se constatou que houve efeito significante entre as formas de propagação e tipos de sistema. Tendo como melhor forma de propagação mini-estaca, onde podese verificar os sistemas solo e semi-hidroponia com melhores índices, com médias de 71,67g e 74,59g respectivamente (Tabela 1), efetivando assim a forma de propagação por mini-estaca como promissora para o parâmetro em questão avaliado, resultado este superior ao de Bandeira (2013) que estudando a produção de massa fresca da parte aérea de estacas uninodais de um acesso de Mentha piperita, obteve média da massa fresca de $45 \mathrm{~g}$ por planta.

Quanto a massa seca, pode-se perceber que houve efeito significativo tanto para forma de propagação, sistemas e a interação entre elas, sobressaindo-se o sistema hidropônico em ambas formas de propagação, apresentando através do desdobramento a forma de propagação através de mini-estacas com melhores médias em relação as cultivadas por semente nesse parâmetro, remetendo mais uma vez a 
qualidade de plantas produzidas por meio desta técnica de cultivo (Tabela 1). Segundo Martínez (2016) a massa seca é mais adequada para a comparação de tratamentos, pois não está sujeita ao efeito da umidade dos tecidos quando somadas a alguma umidade residual, o referido autor em seu trabalho com médias de massas fresca e seca de estacas de Mentha piperita, aos 35 dias pós transplante previamente enraizadas por 28 dias em cinco meios de enraizamento, obteve resultados inferiores aos obtidos no presente trabalho, com média de 7,37g de massa seca por planta, cultivadas em areia adubada.

Para produtividade pode ser verificado interação significante para FP $\times$ S. Onde a forma de propagação por mini-estaca foi superior nas plantas cultivadas por meio de sementes com melhores médias. Para sistema houve significância, onde os sistemas hidropônico e semi-hidropônico apresentaram resultados satisfatórios, superiores ao sistema solo (Tabela 1), para as demais variáveis, valores semelhantes foram obtidos, o que nos mostra que não houve variação entre um sistema e outro, obtendo êxito em cada um deles. Casais et al. (2019) afirmam que no cultivo de hortelã-pimenta (Mentha piperita) em hidroponia sob a técnica do NFT, usualmente são espaçados $25 \mathrm{~cm}$ para a colocação das plantas entre os orifícios. Sendo assim, o cultivo em sistema hidropônico permite um maior adensamento, que pode produzir um maior número de plantas, acarretando em mais produtividade. Carvalho (2015), ressalta que em solo é determinante para aumentar a produção da hortelã-pimenta a necessidade de elevar o teor de MO do solo para se obter culturas com uma elevada produtividade.

Verificou-se efeito significativo entre os fatores forma de propagação e sistemas (Tabela 2) de hortelã-pimenta para as características avaliadas: largura foliar, comprimento foliar, fator de forma, perímetro e área foliar. Foi realizado uma análise de desdobramento para verificar qual fator apresentou melhores resultados para cada característica, havendo efeito significativo para a interação FP x S apenas para a uma das características propostas. Considerando-se a importância do cultivo de plantas medicinais, tornase fundamental a caracterização morfológica de caracteres diretamente relacionados ao crescimento de plantas (GARCIA et al., 2016).

Tabela 2: Indicadores morfológicos em folhas de Hortelã-pimenta, cultivadas por diferentes formas de propagação e sistemas de cultivos, onde LF- Largura foliar, CF- Comprimento foliar, FF- Fator de forma, PM- Perímetro e AF- Área foliar. Paragominas-PA.

\begin{tabular}{|l|l|l|l|l|l|}
\hline SISTEMA & LF $(\mathrm{cm})$ & CF $(\mathrm{cm})$ & FF & PM $(\mathrm{cm})$ & AF $\left(\mathrm{cm}^{2}\right)$ \\
\hline MINI-ESTACA & & & & & \\
\hline Solo & $3,13 \mathrm{bA}$ & $5,19 \mathrm{bA}$ & $1,66 \mathrm{aB}$ & $14,62 \mathrm{bA}$ & $12,43 \mathrm{cA}$ \\
\hline Semi-hidroponia & $4,22 \mathrm{aA}$ & $6,67 \mathrm{aA}$ & $1,58 \mathrm{abB}$ & $19,14 \mathrm{aA}$ & $21,19 \mathrm{bA}$ \\
\hline Hidroponia & $4,44 \mathrm{aA}$ & $6,81 \mathrm{aA}$ & $1,54 \mathrm{bB}$ & $19,29 \mathrm{aA}$ & $22,48 \mathrm{aA}$ \\
\hline SEMENTE & & & & & \\
\hline Solo & $2,11 \mathrm{bB}$ & $3,63 \mathrm{bB}$ & $1,74 \mathrm{aA}$ & $9,66 \mathrm{cB}$ & $6,04 \mathrm{cB}$ \\
\hline Semi-hidroponia & $3,13 \mathrm{aB}$ & $4,98 \mathrm{aB}$ & $1,66 \mathrm{abA}$ & $13,63 \mathrm{bB}$ & $10,61 \mathrm{bB}$ \\
\hline Hidroponia & $3,44 \mathrm{aB}$ & $5,29 \mathrm{aB}$ & $1,59 \mathrm{bA}$ & $15,58 \mathrm{aB}$ & $13,10 \mathrm{aB}$ \\
\hline Forma de propagação & $* *$ & $* *$ & $* *$ & $* *$ & $* *$ \\
\hline Sistema & $* *$ & $* *$ & $* *$ & $* *$ & $* *$ \\
\hline FP $\times$ S & $\mathrm{NS}$ & $\mathrm{NS}$ & $\mathrm{NS}$ & $\mathrm{NS}$ & $* *$ \\
\hline CV $\%)$ & 6,93 & 6,95 & 4,46 & 6,37 & 4,98 \\
\hline
\end{tabular}

Médias seguidas pela mesma letra maiúscula corresponde a forma de propagação não diferem entre si, médias seguidas pela mesma letra minúscula corresponde a um sistema não diferem entre si, pelo teste de Tukey, a 5\% de probabilidade, **=significativo a 5\% de probabilidade; FP x S: Interação forma de propagação e sistema; ns=não significativo.

Para largura foliar, houve efeito significativo para forma de propagação. Observa-se na Tabela 2 que 
forma de propagação através de mini-estaca se mostrou superior em todos os sistemas em relação as plantas conduzidas através de sementes. Com relação ao sistema houve interação significativa, sendo o sistema hidropônico mais promissor em relação aos demais ao se observar as maiores médias, porém resultados parecidos são encontrados nos demais sistemas, demonstrando assim êxito na condução deste trabalho. Barbosa et al. (2018), em seu trabalho com aspectos morfoanatômicos da hortelã-graúda produzida em diferentes tipos de cultivo orgânico, obtiveram para o tratamento orgânico com manejo, valor de 5,81cm para largura de folha, valor este superior ao encontrado neste trabalho, fator que pode ser explicado pela ocasião do referido autor ter coletado as plantas de hortelã provenientes de policultivo com hortaliças, o que pode ter favorecido o aumento foliar das mesmas e também por terem sido adubadas com esterco caprino, ovino e bovino, que contém altas doses de nitrogênio, favorecendo o crescimento da parte vegetativa das plantas.

Para o que se refere a comprimento foliar, não houve interação significante para FP $\times$ S. Apresentando valores significativos para forma de propagação, tendo o cultivo através de mini-estaca como destaque na produção em relação ao cultivo através de sementes. Pode-se observar valores significativos também para sistema, tendo hidroponia uma média de 6,81cm (Tabela 2) e semi-hidroponia apresentando melhores médias quando comparados ao cultivo em solo para as duas formas de propagação, valores esses similares com os de Rosanova et al. (2015) que em sua pesquisa com análise da secagem de folhas e hastes de hortelã em secador tipo cesto rotativo, obtiveram $6,1 \mathrm{~cm}$ de comprimento de folhas em hortelã comum.

Com relação ao fator de forma é possível observar que não houve efeito significativo para a interação entre forma de propagação e sistema. Já para forma de propagação houve efeito significativo tendo majoritariamente o cultivo através de semente com melhores resultados. Em sistema de cultivo também houve significância, apresentando 1.74 (Tabela 2) de média para o cultivo em sistema em solo, demonstrando que há uma diferença na forma da folha quando cultivados por diferentes formas de propagação, onde as folhas através de semente possuem maior comprimento foliar e menor largura, indicando uma folha mais elíptica. Ishikawa (2017) diz que o fator de forma ou índice de afilamento é o quociente do comprimento do limbo foliar por sua largura, que se for igual ou muito próximo a 1,0, indica tendência a um formato circular ou ovalado do limbo foliar, no entanto índices mais elevados indicam uma tendência a um formato elíptico de folhas.

No que concerne a perímetro houve significância para forma de propagação, tendo maior êxito as plantas cultivadas por mini-estaca em relação as cultivadas através de sementes, no entanto a relação FP x $S$ não foi significante. Quanto à sistema houve significância, sendo as plantas produzidas em sistema semihidropônico e hidropônico com melhores médias $19.14 \mathrm{~cm}$ e $19.29 \mathrm{~cm}$ respectivamente (Tabela 2). Ao analisar o perímetro de uma folha pode-se desconsiderar danos por pragas, efetivando assim os valores para a área foliar útil da planta.

Para área foliar, houve interação significativa das formas de propagação e sistemas (Tabela 2), onde tanto o fator forma de propagação como o fator sistema, tiveram interferência nessa variável. Também houve interação significativa para FP x S. Em forma de propagação, o cultivo através de mini-estaca se 
apresentou melhor em comparação ao cultivo por semente. Já o sistema que se mostrou mais promissor para este parâmetro foi o sistema hidropônico com média de $22.48 \mathrm{~cm}^{2}$ de área foliar (Tabela 2) em hortelãpimenta. A área foliar é o parâmetro de maior importância no que se concerne à produção de óleo essencial, pois quanto maior for a área foliar maior será a quantidade de óleos e bioativos extraídos por planta. Pegoraro (2007) afirma que o cultivo com alta densidade de plantas pode reduzir a produção de óleo essencial, porque diminui a área foliar por planta devido à queda das folhas provocada pela umidade do adensamento.

Verificou-se efeito significativo na interação entre os fatores forma de propagação e sistema de hortelã-pimenta (Tabela 3) para as características avaliadas razão de área foliar (RAF), razão de peso foliar (RPF), área foliar especifica (AFE), peso específico da folha (PEF), quantidade de água na parte aérea (QAPA) e índice de área foliar (IAF).

Para razão de área foliar (RAF) houve resultado significativo para a interação entre os fatores, tendo significância para forma de propagação que apresentou o cultivo por mini-estaca como promissor neste parâmetro. Em sistema houve significância tendo destaque o sistema semi-hidropônico com melhores médias para as duas formas de propagação com valores de 1,98 e 1,93 dm² g- $^{1}$ respectivamente (Tabela 3). Costa et al. (2012) observou em sua pesquisa maior RAF no crescimento das plantas de hortelã-pimenta, quando cultivadas sob malhas. Henrique et al. (2011), citam que a RAF expressa um componente morfofisiológico que representa uma relação entre a área foliar, esta é responsável pela interceptação da energia luminosa, $\mathrm{CO}_{2}$ e a massa de matéria seca total que é resultante da fotossíntese.

Tabela 3: Índice de qualidade de plantas de Hortelã-pimenta, cultivadas por diferentes formas de propagação e sistemas de cultivos, onde RAF- Razão de área foliar, RPF- Razão de peso foliar, AFE- Área foliar especifica, PEF- Peso específico da folha, QAPA- Quantidade de água na parte aérea, IAF- Índice de área foliar. Paragominas-PA.

\begin{tabular}{|l|l|l|l|l|l|l|}
\hline SISTEMA & RAF $\left(\mathrm{dm}^{2} \mathrm{~g}^{-}\right)$ & RPF $\left(\mathrm{g} \mathrm{g}^{-}\right)$ & AFE $\left(\mathrm{dm}^{2} \mathrm{~g}^{-}\right)$ & PEF $\left(\mathrm{g} \mathrm{dm}^{-}\right)$ & QAPA $(\mathrm{g})$ & IAF $\left(\mathrm{cm}^{2} / \mathrm{planta}\right)$ \\
\hline MINI-ESTACA & & & & & & \\
\hline Solo & $1,86 \mathrm{bA}$ & $2,24 \mathrm{bB}$ & $1,86 \mathrm{bA}$ & $0,53 \mathrm{bB}$ & $65,11 \mathrm{aA}$ & $0,77 \mathrm{bA}$ \\
\hline Semi-hidroponia & $1,98 \mathrm{aA}$ & $4,56 \mathrm{aA}$ & $1,98 \mathrm{aA}$ & $0,51 \mathrm{cB}$ & $63,83 \mathrm{aA}$ & $1,34 \mathrm{aA}$ \\
\hline Hidroponia & $1,75 \mathrm{bA}$ & $2,16 \mathrm{bB}$ & $1,75 \mathrm{cA}$ & $0,57 \mathrm{aB}$ & $39,62 \mathrm{bB}$ & $1,41 \mathrm{aA}$ \\
\hline SEMENTE & & & & & & \\
\hline Solo & $0,52 \mathrm{cB}$ & $3,14 \mathrm{aA}$ & $0,52 \mathrm{cB}$ & $1,78 \mathrm{aA}$ & $26,63 \mathrm{cB}$ & $0,34 \mathrm{bB}$ \\
\hline Semi-hidroponia & $1,93 \mathrm{aB}$ & $2,09 \mathrm{cB}$ & $1,93 \mathrm{aB}$ & $0,53 \mathrm{bA}$ & $41,79 \mathrm{bB}$ & $0,67 \mathrm{aB}$ \\
\hline Hidroponia & $1,17 \mathrm{bB}$ & $2,52 \mathrm{bA}$ & $1,17 \mathrm{bB}$ & $0,86 \mathrm{aA}$ & $50,18 \mathrm{aA}$ & $0,82 \mathrm{aB}$ \\
\hline Forma de propagação & $* *$ & $* *$ & $* *$ & $* *$ & $* *$ & $* *$ \\
\hline Sistema & $* *$ & $* *$ & $* *$ & $* *$ & $* *$ & $* *$ \\
\hline FP $\times$ S & $* *$ & $* *$ & $* *$ & $* *$ & $* *$ & $* *$ \\
\hline CV (\%) & 11,94 & 6,40 & 11,94 & 11,16 & 10,61 & 11,20 \\
\hline
\end{tabular}

Médias seguidas pela mesma letra maiúscula corresponde a forma de propagação não diferem entre si, médias seguidas pela mesma letra minúscula corresponde a um sistema não diferem entre si, pelo teste de Tukey, a $5 \%$ de probabilidade, **=significativo a $5 \%$ de probabilidade; FP x S: Interação forma de propagação e sistema; ns=não significativo.

No que concerne à razão de peso foliar (RPF), houve uma interação significativa entre as formas de propagação, onde o meio de propagação através de sementes apresentou melhores resultados quando comparado ao meio de propagação via mini-estaca. Já para sistema houve interação significativa, com solo e semi-hidroponia tendo destaque na produção (Tabela 3). Segundo Benincasa (2003), se considerarmos as folhas como centro de produção de biomassa bem como o resto da planta vai depender da exportação de material da folha, a razão de peso foliar expressa a fração de biomassa que não foi exportada das folhas para 
outras partes da planta. Ou seja, pode-se observar que o aumento da RPF indica que a proporção da biomassa que está retida nas folhas e a exportada para outras partes depende da interceptação de radiação solar, bem como o sistema em que a planta está inserida.

Houve resposta significante a interação entre os fatores FP x S para o parâmetro área foliar especifica (AFE), onde a partir do desdobramento pode-se verificar efeito significativo para forma de propagação em que o cultivo por mini-estaca obteve sucesso em comparação ao por via semente. Para sistema, pode-se observar na Tabela 3, que o cultivo por semi-hidroponia apresentou melhores resultados com 1,98 $\mathrm{dm}^{2} \mathrm{~g}^{1}$ de média quando cultivado por mini-estaca. Benincasa (2003), ressalta ainda que a área específica das folhas (AFE) relaciona os componentes morfoanatômicos das folhas, sendo ele um indicativo da espessura das folhas para estimar a relação entre a proporção da superfície assimilatória e dos tecidos de sustentação e condutoras da folha. Sendo assim pode-se estimar que folhas produzidas em sistema de solo por semente são bem menos espessas que as folhas produzidas através de mini-estaca em sistema semi-hidropônico (Tabela 3).

Para o que se refere a peso específico da folha (PEF), houve efeito significativo para a interação entre os fatores FP x S (Tabela 3), resultando a partir do desdobramento dos dados, resultado significativo para forma de propagação em que plantas produzidas por semente mostram-se superiores as produzidas via miniestaca. Quanto ao que compete a sistema, há um efeito significativo. Plantas cultivas em sistema solo apresentaram bons índices. Pegoraro (2010), cita que houve um aumento no peso específico foliar com maior alocação de biomassa foliar em plantas que receberam adubação. Indicando que a adubação pode ter sido relevante para os resultados aqui obtido para o cultivo em solo de hortelã-pimenta.

Em quantidade de água na parte aérea (QAPA), houve efeito significativo para interação entre os fatores, onde para forma de propagação, mini-estaca apresentou melhores valores em comparação a semente. Já para o que se refere a sistema de cultivo houve resposta significativa, apresentando com média de $65,11 \mathrm{~g}$ as plantas produzidas em solo por mini-estaca, êxito no referido parâmetro (Tabela 3). Guimarães et al. (2008), citam que em média, as partes verdes da maioria das plantas têm um teor de água que vai de 80 a 90\%, variando de acordo com as condições hídricas ambientais, onde as condições hídricas nos tecidos das plantas podem ser melhor avaliadas pelo potencial total de água na planta.

Para índice área foliar (IAF) pode-se observar que há significância entre a interação da forma de propagação e sistema, onde para forma de propagação as plantas cultivadas por mini-estaca apresentam médias superiores a todos os sistemas utilizados para produção via semente. Quanto à sistema houve reposta significativa, onde os sistemas hidropônico e semi-hidropônico apresentaram melhores médias com 1,41 e 1,34 $\mathrm{cm}^{2} /$ planta respectivamente (Tabela 3). O Índice de Área Foliar (IAF) é uma variável importante para monitorar o crescimento das culturas (ROCHA et al., 2016), eles obtiveram uma variável que está diretamente relacionada ao vigor das plantas e sua produtividade além de representar a eficiência na interceptação e utilização da radiação solar (SOUZA et al., 2018). Dorneles et al. (2019), dizem que o IAF pode ser utilizado para representar a eficiência fotossintética, assim como para análise do crescimento e também como fator condicionante da produtividade, pois através do IAF é definida a capacidade do dossel em interceptar a 
radiação solar, converter em matéria seca através da fotossíntese e determinar o potencial produtivo da cultura.

Ao analisar a clorofila observou-se que não houve resultados significativos para nenhuma forma de propagação, isto pode ser explicado pelo fato do cultivo ter sido conduzido em clima tropical, com altas temperaturas e grande intensidade de raios solares, o que permite uma melhor produção de pigmentos fotossintéticos. A absorção de clorofila (a) não apresentou variância entre as formas de propagação analisadas (Tabela 4), muito provavelmente isto se deu pela uniformidade de disponibilidade de luz, pois as plantas receberam radiação em quantidade uniforme, com sombreamento parcial feito principalmente no cultivo hidropônico e semi-hidropônico, com exceção do cultivo em solo que foi realizado a pleno sol. A clorofila $(b)$ apresentou leve variação, tendo resultados significantes quando comparados. Este tipo de clorofila é considerado um pigmento fotossintético acessório e tem função de ampliar a faixa de luz absorvida pela planta (MESQUITA, 2005).

Para clorofila $(a)$ houve efeito significativo para a interação entre os fatores forma de propagação e sistema, onde é possível observar que o cultivo por via de sementes favoreceu a absorção da clorofila $(a)$ no cultivo em solo (Tabela 4). Quanto à sistema também apresentou respostas significativas, tendo o sistema solo e semi-hidropônico com boas médias apresentadas. Uma maior quantidade de folhas observadas (Tabela 1) nos sistemas hidropônico e semi-hidropônico pode explicar uma maior capacidade de absorção de radiação solar, ampliando assim a faixa de absorção de luz para a clorofila (a). Raven et al. (2007), explanam que a clorofila pode ser classificada como clorofila $a$ que é a principal responsável pela coloração verde das plantas e pela realização da fotossíntese. Ferreira et al. (2015) observaram que a análise da fluorescência da clorofila $a$ vem sendo utilizada para melhorar o entendimento dos mecanismos da fotossíntese, assim como na avaliação da capacidade fotossintética das plantas que podem ser alteradas por estresses bióticos ou abióticos.

Tabela 4: Índice de clorofila a, b e total de plantas de Hortelã-pimenta, cultivadas por diferentes formas de propagação e sistemas de cultivos. Paragominas-PA.

\begin{tabular}{|c|c|c|c|}
\hline \multirow[t]{2}{*}{ SISTEMA } & \multicolumn{3}{|c|}{ CLOROFILA (ICF) } \\
\hline & A & B & TOTAL \\
\hline \multicolumn{4}{|l|}{ MINI-ESTACA } \\
\hline Solo & $293,77 a B$ & $77,95 \mathrm{aB}$ & $371,70 \mathrm{aB}$ \\
\hline Semi-hidroponia & $297,78 \mathrm{aA}$ & $83,23 a A$ & $381,25 a A$ \\
\hline Hidroponia & $268,05 b B$ & $60,63 \mathrm{bB}$ & $328,10 \mathrm{bB}$ \\
\hline \multicolumn{4}{|l|}{ SEMENTE } \\
\hline Solo & $320,57 a A$ & $90,32 a A$ & $415,66 a A$ \\
\hline Semi-hidroponia & $268,12 b B$ & $66,37 \mathrm{bB}$ & $335,17 \mathrm{bB}$ \\
\hline Hidroponia & $275,08 \mathrm{bA}$ & $71,55 \mathrm{bA}$ & $346,42 b A$ \\
\hline Forma de propagação & NS & NS & NS \\
\hline Sistema & $* *$ & $* *$ & $* *$ \\
\hline $\mathrm{FP} \times \mathrm{S}$ & $* *$ & $* *$ & $* *$ \\
\hline CV (\%) & 5,39 & 11,60 & 5,42 \\
\hline
\end{tabular}

Médias seguidas pela mesma letra maiúscula corresponde a forma de propagação não diferem entre si, médias seguidas pela mesma letra minúscula corresponde a um sistema não diferem entre si, pelo teste de Tukey, a $5 \%$ de probabilidade, ${ }^{* *}=$ significativo a $5 \%$ de probabilidade; FP x S: Interação forma de propagação e sistema; ns=não significativo.

Quanto a clorofila (b), não houve efeito significativo para forma de propagação dentro de cada sistema, apresentando valores similares para todos os sistemas. Já quando realizado desdobramento de 
dados observa-se para sistema resultados significativos, onde solo apresentou média superior aos demais sistemas com 90,32 ICF (Tabela 4) no cultivo por via semente, isso se deve ao fato que as plantas produzidas através deste cultivo permaneceram durante todo o seu ciclo até a colheita a pleno sol com boa uniformidade de disponibilidade de luz, o que permitiu folhas com alta absorção de clorofila (b). Cunha et al. (2019) obtiveram em seu experimento analisando a influência da qualidade de luz no crescimento e acúmulo de voláteis de Mentha spicata cultivada in vitro, observou que com relação aos pigmentos fotossintéticos, foi possível observar que as diferentes qualidades de luz afetam a concentração de clorofila $b$. Armond et al. (2016) analisaram o desenvolvimento inicial de plantas de abobrinha italiana cultivada com húmus de minhoca onde obtiveram o maior valor para o teor de clorofila $b$ na dose de $644 \mathrm{~g}$ de adubação orgânica proporcionando valor estimado em $13,80 \mathrm{mg} / \mathrm{g}$, valor esse abaixo dos encontrados nesta pesquisa.

Quanto ao que concerne a clorofila total, houve interação significativa entre FP $\times$ S. Onde pode se observar na Tabela 4 valores significativos para sistema, tendo como sistema mais promissor neste parâmetro solo seguido da semi-hidroponia com melhores índices (Tabela 4). Não se obteve resultados significativos para forma de propagação, demostrando assim resultados bem similares na variável analisada. Larcher (2000), diz que o acúmulo de clorofila total nas folhas sombreadas está relacionado com a pequena quantidade de luz disponível neste ambiente, já que absorção deste recurso depende da concentração de pigmentos fotossintéticos, fato este contraditório aos dados obtidos neste trabalho, onde pode se observar melhores valores para clorofila total no sistema em solo, cultivado a pleno sol. Araújo et al. (2019) observaram que é maior a concentração de nitrogênio em plantas que apresentam maior quantidade de clorofila total, o que pode explicar o fato das plantas cultivadas em solo terem se sobressaído as demais, já que durante seu ciclo foram realizadas adubações periódicas de nitrogênio.

\section{CONCLUSÕES}

A forma de propagação utilizada através de mini-estaca se mostrou eficiente para o cultivo de hortelã-pimenta, promovendo um menor ciclo em todos os sistemas observados, sendo em hidroponia 43 dias de ciclo, semi-hidroponia e solo ambas com 45 dias ciclo, na produção via semente as plantas apresentaram em hidroponia 72 dias de ciclo, semi-hidroponia 83 e solo 102 dias de ciclo, efetivando assim a mini-estaca no cultivo da hortelã como promissora e abrindo oportunidade de maior quantidade de plantio entre as janelas de produção com seu máximo potencial produtivo.

As maiores produtividades foram encontradas nos sistemas solo e semi-hidroponia, através da forma de propagação por mini-estaca, destacando mais uma vez o efeito positivo na interação entre essa forma de propagação a esses meios de cultivos na produção dessa cultura, desde modo nos parâmetros morfofisiológicos o cultivo em sistema hidropônico e semi-hidropônico em sua generalidade foi o que apresentou melhores condições para a produção de plantas de hortelã-pimenta através de mini-estaca, demonstrando uma forte interação entre esses fatores para um bom cultivo. Os valores de clorofila não divergiram quanto as formas de propagação evidenciando tanto mini-estaca quanto semente, boas condutoras no cultivo de plantas na produção de pigmentos fotossintéticos. Em relação ao sistema, 
surpreendentemente o cultivo em solo foi o que se mostrou mais promissor.

\section{REFERÊNCIAS}

ALMEIDA, A. M. B.. Viabilidade agroeconômica da hortelã (Mentha piperita L.) em dois cultivos sucessivos sob doses de jitirana e épocas de colheita. Dissertação (Mestrado em Sistemas Agroindustriais) - Universidade Federal de Campina Grande, Pombal, 2018.

ARAÚJO, L. L. N.; MELO, H. C.; CASTIGLIONI, GONÇALVES. G. L. L. A.. Intensidade de radiação influenciando características morfofisiológicas em folhas de Tetradenia riparia (Hochst.) Codd. Iheringia, Série Botânica, v.74, n.1, p.1-6, 2019. DOI: http://dx.doi.org/10.21826/2446$\underline{82312019 v 74 \mathrm{e} 2019001}$

ARMOND, C.; OLIVEIRA, V. C.; GONZALEZ, S. D. P.; OLIVEIRA, F. E. R.; SILVA, R. M.; LEAL, T. T. B.; REIS, A. S.; SILVA, F.. Desenvolvimento inicial de plantas de abobrinha italiana cultivada com húmus de minhoca. Horticultura Brasileira, v.34, n.3, p.439-442, 2016. DOI: http://dx.doi.org/10.1590/s0102-05362016003022

BANDEIRA, R. A.. Produção de biomassa de Mentha piperita L. em casa de vegetação do tipo 'glasshouse'. Monografia (Bacharelado em Agronomia) - Universidade de Brasília, Brasília, 2013.

BARBOSA, L. S.; BEZERRA, A. C.; AZEVEDO, C. F.. Aspectos morfoanatômicos da hortelã-graúda produzida em diferentes tipos de cultivo orgânico. Cadernos de Agroecologia, Brasília, v.13, n.1, p.1-7, 2018.

BENINCASA, M. M. P.. Análise de crescimento de plantas: noções básicas. Jaboticabal: Fundação Nacional de Ensino e Pesquisa, 2003.

BEZERRA NETO, E.; BARRETO, L. P.. As técnicas de hidroponia. Anais da Academia Pernambucana de Ciência Agronômica, Recife, v.8, n.1, p.107-137, 2012.

BRASIL. Ministério da Saúde. Monografia da espécie Mentha x piperita I. (hortelã pimenta). Brasília: Anvisa, 2015.

CARVALHO, S. C. R. S.. Efeito da correção orgânica e da fertirrigação na cultura da hortelã-pimenta (Mentha $x$ piperita) no modo de produção biológico. Dissertação (Mestrado em Agricultura Biológica) - Instituto Politécnico de Viana do Castelo, Viana do Castelo, 2015.

CASAIS, L. K. N.; AVIZ, R. O.; VASCONCELOS, E. S.; BORGES, L. S.. Hidroponia pode aumentar produtividade em até 50\%. Uberlândia: Campo \& Negócio, 2019a.

COSTA A. G.; CHAGAS, J. H.; PINTO, J. E. B. P.; BERTOLUCCI, S. K. V.. Crescimento vegetativo e produção de óleo essencial de hortelã-pimenta cultivada sob malhas. Pesquisa Agropecuária Brasileira, v.47, p.534-540, 2012.

CUNHA, S. H. B.; SILVA, S. T.; BERTOLUCCI, S. K. V.; CARVALHO, A. A.; ROCHA, T. T.; PINTO, J. E. B. P.. Influência da qualidade de luz no crescimento e acúmulo de voláteis de Mentha spicata cultivada in vitro. Scientia Plena, v.15, n.9, p.1-11, 2019. DOI:

http://dx.doi.org/10.14808/sci.plena.2019.090201

DINALLI, R. P.; CASTILHO, R. M. M.; GAZOLA, R. N.; CELESTRINO, T. S.; GONZAGA, D. A.; FERREIRA, A. F. A.. Produção de mudas de Zamioculcas zamiifolia por estaca foliar. Tecnologia \& Ciências Agropecuária, João Pessoa, v.7, n.3, p.7-12, 2013.

DORNELES, M. M.; BRITO, G. H. M.. Índice de área foliar e suas aplicações na agricultura. In: SEMANA AGRONÔMICA TECNOLOGIA E SUSTENTABILIDADE NA AGROPECUÁRIA DO CERRADO, 8. Anais. Goianésia: Seagro, 2019. p.1.

EMBRAPA. Empresa Brasileira de Pesquisa Agropecuária. Sistema Brasileiro de Classificação de Solos. Rio de Janeiro: Embrapa Solos, 2008.

FERREIRA, E. A.; MATOS, C. C.; BARBOSA, E. A.; SILVA, D. V.; SANTOS, J. B.; PEREIRA, G. A. M.; FARIA, A. T.; SILVA, C. T.. Respostas fisiológicas da mandioca à aplicação de herbicidas. Semina: Ciências Agrárias, Londrina, v.36, n.2, p.645-655, 2015. DOI: http://dx.doi.org/10.5433/1679$\underline{0359.2015 v 36 n 2 p 645}$

GARCIA, C. S.; SILVA, R. M.; VIANA, V. E.; BUSANELLO, C.; PENAGORO, C.; OLIVEIRA, A. C.; MAIA, L. C.. Efeito da radiação gama na germinação e desenvolvimento de sementes de camomila (Matricaria recutita L.). In: JORNADA DE PÓS-GRADUAÇÃO E PESQUISA, 13. Anais, 2016.

GRANDI, T. S. M.. Tratado das Plantas Medicinais: mineiras, nativas e cultivadas. Belo Horizonte: Adequatio Estúdio. 2014.

GUEDES, J. I. S.. A influência do modo de produção (ar livre e estufa em solo) e da variedade na produtividade em matéria vegetal verde, no rendimento na extração de óleo essencial e nas características qualitativas do óleo essencial do Poejo (Mentha pulegium L.). Dissertação (Mestrado em Engenharia Agronômica) - Universidade do Porto, Porto, 2015.

GUIMARÃES, C. M.; STONE, L. F.. Métodos de Avaliação das Condições Hídricas das Plantas. Santo Antônio de Goiás: Embrapa, 2008.

HENRIQUE, P. C.; ALVES, J. D.; DEUNER, S.; GOULART, P. F. P.; LIVRAMENTO, D. E.. Aspectos fisiológicos do desenvolvimento de mudas de café cultivadas sob telas de diferentes colorações. Pesquisa Agropecuária Brasileira, Brasília, v.46, n.5, p.458-465, 2011.

ISHIKAWA, F. Y.. Caracterização morfológica de genótipos de Ocimum basilicum L. Na fase vegetativa. Monografia (Bacharelado em Agronomia) - Universidade de Brasília, Brasília, 2017.

LARCHER, W.. Ecofisiologia vegetal. São Carlos: Rima, 2000.

LOURENCO, C.. Empreender na Produção de Plantas Aromáticas e Medicinais em Portugal. Boas práticas na 
aquisição de plantas aromáticas, medicinais e condimentares em viveiro. Lisboa, 2015.

MARTínEZ, C. A. G.. Principais componentes do óleo essencial de acessos de Mentha spp em Brasília e estudo da propagação vegetativa. Dissertação (Mestrado em Agronomia) - Universidade de Brasília, Brasília, 2016.

MESQUITA, R. C.. Caracterização fotoacústica de plantas crescidas sob diferentes condições de luminosidade. Dissertação (Mestrado em Física da Matéria Condensada) Universidade Estadual de Campinas, Campinas, 2005.

PARDOSSI, A.; INCROSSI, L.; SALAS, M. C.; GIANQUINTO, G.. Managing mineral nutrition in soilless culture. In: ORSINI, F., DUBBELING, M.; ZEEUW, H.; GIANQUINTO, G.. Rooftop urban agriculture. Urban Agriculture. Springer, 2017. p.147166.

PEGORARO, R. L.. Avaliação do crescimento e produção de óleos essenciais em plantas de Mentha x piperita L. Var. Piperita (lamiaceae) submetidas a diferentes níveis de luz e nutrição. Dissertação (Mestrado em Biologia Vegetal) Universidade Federal de Santa Catarina, Florianópolis, 2007.

PEGORARO, R. L.; FALKENBERG, M. B.; VOLTOLINI, C. H.; SANTOS, M.; PAULILO, M. T. S.. Produção de óleos essenciais em plantas de Mentha x piperita L. var. piperita (Lamiaceae) submetidas a diferentes níveis de luz e nutrição do substrato. Revista Brasileira de Botânica, v.33, n.4, p.631637, 2010.

RAVEN, P. H.; EVERT, R. F.; EICHHORN, S. E.. Biologia

Vegetal. 7 ed. Rio de Janeiro: Guanabara Koogan S. A., 2007.
ROCHA, M. G.; PAULO, R. L.; NOGUCHI, R. Y. O.; AMARAL, L. R.. Avaliação de métodos de determinação de índice de área foliar da cana-de-açúcar de forma espacializada. In: CONGRESSO BRASILEIRO DE AGRICULTURA DE PRECISÃO. Anais. Goiânia: ConBAP, 2016.

RODRIGUES, T. E.; SILVA, J. M. L.; GAMA, J. R. N. F.; VALENTE, M. A.; OLIVEIRA JUNIOR, R. C.. Zoneamento Agroecológico do município de Paragominas, Estado do Pará. BoletimTécnico Belém: Embrapa Amazônia Oriental, 2002.

ROSANOVA, A. H.; FERREIRA, M. C.. Análise da secagem de folhas e hastes de hortelã em secador tipo cesto rotativo. In: CONGRESSO BRASILEIRO DE SISTEMAS PARTICULADOS, 37. Anais. São Carlos, 2015. p.1-10. DOI: http://dx.doi.org/10.5151/enemp2015-se-343

SIZENANDO NETO, J.; OLIVEIRA, A. A. S.; PAIVA, M. R. F. C.; NOGUEIRA, H. C.. Os efluentes gerados no cultivo hidropônico e os impactos causados pelo seu descarte inadequado. In: SIMPÓSIO DE MANEJO DE SOLO E ÁGUA, 1; WORKSHOP DE MANEJO DE ÁGUA DE QUALIDADE INFERIOR NA AGRICULTURA, 2; ENCONTRO DO PROJETO CASADINHO/PROCAD/CNPq, 1. Anais. Mossoró: UFERSA, 2017.

SOUZA, A. L. P.; COSTA, M. M.; SENA JUNIOR, D. G.; PAZ, R. B. O.. Análise de três métodos de obtenção do índice de área foliar para cultura da soja. In: SIMPÓSIO MATO-GROSSENSE DE MECANIZAÇÃO AGRÍCOLA E AGRICULTURA DE PRECISÃO. Anais. Sinop, 2018. p.4.

A CBPC - Companhia Brasileira de Produção Científica (CNPJ: 11.221.422/0001-03) detém os direitos materiais desta publicação. Os direitos referem-se à publicação do trabalho em qualquer parte do mundo, incluindo os direitos às renovações, expansões e disseminações da contribuição, bem como outros direitos subsidiários. Todos os trabalhos publicados eletronicamente poderão posteriormente ser publicados em coletâneas impressas sob coordenação da Sustenere Publishing, da Companhia Brasileira de Produção Científica e seus parceiros autorizados. Os (as) autores (as) preservam os direitos autorais, mas não têm permissão para a publicação da contribuição em outro meio, impresso ou digital, em português ou em tradução. 